\begin{tabular}{|l|l|l|}
\hline Received: Maret 2020 & Accepted: April 2020 & Published: April 2020 \\
\hline
\end{tabular}

\title{
Analisis Kuat Geser Tanah Lempung Menggunakan Kapur dan Petrasoil
}

\author{
Indrayani $^{1}{ }^{* *}$, Andi Herius ${ }^{1}$, Putra Nanda Zeri ${ }^{1}$, Nurman Fernando ${ }^{1}$ \\ ${ }^{1 * 2,3,4}$ Jurusan Teknik Sipil, Politeknik Negeri Sriwijaya \\ *iin_indrayani@polsri.ac.id
}

\begin{abstract}
Several studies have added lime, fly ash, or gypsum to clay soils to increase the shear strength of relatively low clay soils. The addition of lime and petrasoil as solvents in water was carried out in this study, where petrasoil is often used in Indonesian road construction works. This study aims to obtain the effect of adding lime and petrasoil to the shear strength of clay. The tests consists of the index properties, seive analysis, atterberg limits, soil compaction, and shear strength testing, based on Standar Nasional Indonesia (SNI) and American Society for Testing and Materials (ASTM). Mixed variations consist of 6, namely: (i) soil + petrasoil; (ii) soil $+10 \%$ lime + petrasoil; (iii) soil $+15 \%$ lime + petrasoil; (iv) soil $+20 \%$ lime + petrasoil; (v) soil $+10 \%$ lime + water; (vi) soil + water; all variations without ripening. The test results showed an increase in the value of soil cohesion in the addition of petrasoil and lime variations of $20 \%$, amounting to $52.41 \mathrm{Kpa}$. While the angle of shear of the soil increased with the addition of lime at a variation of $10 \%$ both with water and with petrasoil, which amounted to $35.10 \%$. This shows an increase in soil shear strength with the addition of petrasoil and lime to the soil.
\end{abstract}

Keywords : Clay, Lime, Petrasoil, Shear Strength

\begin{abstract}
Abstrak
Beberapa penelitian telah menambahkan kapur, fly ash, ataupun gypsum pada tanah lempung untuk meningkatkan kekuatan geser tanah lempung yang relatif rendah. Pada penelitian ini dilakukan penambahan dengan kapur dan petrasoil sebagai pelarut dalam air, dimana petrsoil ini sering digunakan dalam pekerjaan-pekerjaan pembangunan jalan Indonesia. Penelitian ini bertujuan untuk mendapatkan pengaruh penambahan kapur dan petrasoil terhadap kekuatan geser tanah lempung. Pengujian yang dilakukan meliputi pengujian indeks properties, analisa saringan, batas-batas atterberg, uji pemadatan tanah, dan pengujian kekuatan geser, dengan berpedoman pada Standar Nasional Indonesia (SNI) dan American Society for Testing and Materials (ASTM). Adapun variasi campuran terdiri dari 5, yaitu: (i) tanah + petrasoil; (ii) tanah + kapur $10 \%$ + petrasoil; (iii) tanah + kapur $15 \%+$ petrasoil; (iv) tanah + kapur $20 \%+$ petrasoil; (v) tanah + kapur $10 \%+$ air, (vi) tanah + air, keseluruhan campuran ini tanpa pemeraman. Dari pengujian diperoleh hasil terjadi peningkatan nilai kohesi tanah pada variasi penambahan petrasoil dan kapur 20\%, yaitu sebesar 52,41 Kpa, sedangkan pada sudut geser tanah penambahan kapur tertinggi pada variasi $10 \%$ baik dengan air maupun dengan petrasoil, yaitu sebesar 35,10\%. Hal ini menunjukkan terjadinya peningkatan kuat geser tanah dengan penambahan petrasoil dan kapur pada tanah.
\end{abstract}

Kata kunci : Lempung, Kapur, Petrasoil, Kuat Geser

\section{Pendahuluan}

Kuat geser tanah merupakan perlawanan yang ditimbulkan dari butir-butir tanah terhadap suatu tarikan ataupun desakan [1], dimana terjadi gesekan antara butiran tanah yang berbanding lurus dengan tegangan normal pada bidang gesernya. Tanah lempung yang banyak terdapat di Provinsi Sumatera Selatan merupakan jenis tanah kohesif dengan kuat geser rendah dan kompresibilitas yang tinggi, sehingga dapat mengakibatkan sering 
terjadinya penurunan pada bangunanbangunan diatasnya [2].

Tanah lempung memiliki kandungan air yang besar pada kondisi basah, sehingga pada kondisi ini tanah lempung memiliki kemampuan yang sangat rendah dalam mendukung beban diatasnya. Beberapa penelitian telah dilakukan untuk meningkatkan daya dukung tanah ataupun kekuatan geser tanah terhadap tanah lempung diantaranya dengan menambahakan bahan tambah fly ash, kapur, petrasoil, ataupun gypsum $[3][4][5][6][8] . \quad$ Penelitian terdahulu menjadikan dasar dalam melakukan penelitian ini dengan menambahkan kapur dan petrasoil pada tanah, dimana material petrasoil ini sudah sering digunakan dalam kegiatan-kegiatan konstruksi di Indonesia, diantaranya Proyek Peningkatan Jalan Tanah Tabarfane-Hokmar (Chemical Petrasoil) di Kecamatan Aru Selatan Timur, Kepulauan Aru. Tujuan penelitian ini adalah untuk mendapatkan pengaruh penambahan kapur dan petrasoil terhadap kekuatan geser pada tanah lempung.

\section{Metoda Penelitian}

\subsection{Lokasi Penelitian}

Penelitian ini merupakan penelitian laboratorium yang dilakukan di Laboratorium Uji Bahan Politeknik Negeri Sriwijaya, sedangkan lokasi pengambilan material dilakukan di Kecamatan Tanjung Lago, Kabupaten Banyuasin, Provinsi Sumatera Selatan. Pengambilan sampel tanah dapat dilihat pada Gambar 1.

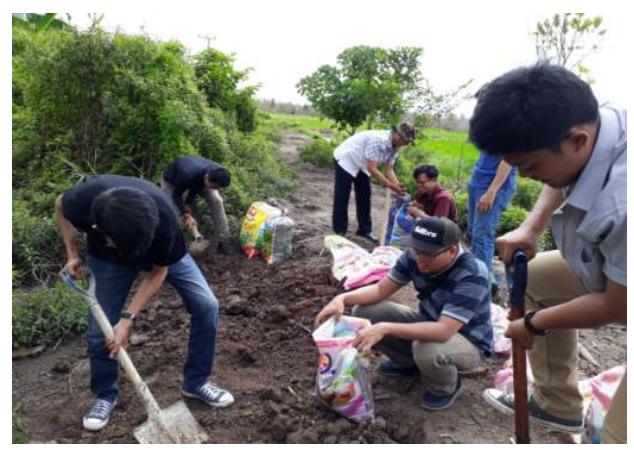

Gambar 1. Pengambilan Sampel Tanah

\subsection{Variasi Campuran}

Keseluruhan pengujian dan analisa yang dilakukan mengacu pada pedoman ASTM dan SNI. Pengujian indeks propertis, batas atterberg dan analisa saringan menggunakan sampel tanah asli dan air PDAM, sedangkan pengujian pemadatan dan kekuatan geser menggunakan petrasoil dengan perbandingan campuran petrasoil : air $=1 \mathrm{~kg}: 1000$ liter, selanjutnya campuran terhadap keseluruhan bahan tambah dilakukan dalam 6 variasi, yaitu: (i) tanah + petrasoil; (ii) tanah + kapur $10 \%+$ petrasoil; (iii) tanah + kapur $15 \%+$ petrasoil; (iv) tanah + kapur 20\% + petrasoil; (v) tanah + kapur 10\%; (vi) tanah + air. Kapur dan petrasoil yang dicampurkan kedalam tanah lempung tanpa pemeraman.

\subsection{Metode Analisis}

Penelitian ini dimulai dari pengambilan sampel tanah, pengujian berat jenis tanah, pengujian batas atterberg, analisa saringan, pengujian pemadatan, dan pengujian kekuatan geser tanah untuk mendapatkan pengaruh penambahan kapur dan petrasoil terhadap kekuatan geser tanah lempung.

\section{Hasil Penelitian}

\subsection{Hasil Pengujian Indeks Propertis}

Dari hasil pengujian indeks properties didapatkan hasil seperti pada Tabel 1.

Tabel 1. Hasil Pengujian Indeks Porpertis

\begin{tabular}{ccc}
\hline No. & Variabel & Hasil \\
\hline 1 & Berat Jenis & 2,60 \\
2 & Batas Cair & $63,28 \%$ \\
3 & Batas Plastis & $42,95 \%$ \\
4 & Indeks Plastisitas & $20,32 \%$ \\
5 & Lolos saringan \#4 & $100 \%$ \\
6 & Lolos saringan \#200 & $79,98 \%$ \\
\hline
\end{tabular}

Dari hasil pada Tabel 2 dapat dilihat bahwa tanah yang akan digunakan pada penelitian termasuk dalam klasifikasi tanah berlempung, dengan ukuran butiran berkisar antara $<0,002 \mathrm{~mm}$ sampai dengan 2,00 $\mathrm{mm}$. 


\subsection{Hasil Pengujian Pemadatan}

Pemadatan dilakukan dalam 6 variasi, untuk menadapatkan kadar air optimum dan berat isi kering tanah dari setiap variasi. Nilai kadar air optimum dan berat isi kering dapat dilihat pada Tabel 2, Gambar 2, dan Gambar 3.

Tabel 2. Hasil Pengujian Pemadatan

\begin{tabular}{|c|c|c|c|}
\hline No. & Variasi & $\begin{array}{c}\text { Kadar Air } \\
\text { Optimum } \\
\text { (Wopt) } \\
\%\end{array}$ & $\begin{array}{c}\text { Berat Isi } \\
\text { Kering } \\
\gamma d \text { max) } \\
\mathrm{gr} / \mathrm{cm}^{3}\end{array}$ \\
\hline 1 & Tanah + Air & 15,76 & 1,286 \\
\hline 2 & $\begin{array}{l}\text { Tanah }+ \\
\text { Petrasoil }\end{array}$ & 20,01 & 1,264 \\
\hline 3 & $\begin{array}{l}\text { Tanah }+ \\
\text { Kapur } 10 \%+ \\
\text { Air }\end{array}$ & 21,99 & 1,434 \\
\hline 4 & $\begin{array}{l}\text { Tanah + } \\
\text { Kapur 10\%+ } \\
\text { Petrasoil }\end{array}$ & 24,27 & 1,307 \\
\hline 5 & $\begin{array}{l}\text { Tanah + } \\
\text { Kapur 15\%+ } \\
\text { Petrasoil }\end{array}$ & 18,50 & 1,250 \\
\hline 6 & $\begin{array}{l}\text { Tanah }+ \\
\text { Kapur 20\%+ } \\
\text { Petrasoil }\end{array}$ & 20,96 & 1,210 \\
\hline
\end{tabular}

Dari hasil pemadatan kadar air optimum pada Tabel 2, rata-rata tanah dengan campuran kapur memiliki kadar air diatas $20 \%$, sedangkan tanah yang dicampur dengan air memiliki kadar air 15,26\%, nilai ini lebih rendah jika dibandingkan dengan tanah yang dicampurkan dengan petrasoil, yaitu sebesar $20,14 \%$. Sedangkan pada berat isi tanah, yang memiliki berat isi tertinggi adalah tanah dengan campuran air yaitu sebesar 1,767 gram/cm3, sedangkan tanah yang dicampur memiliki nilai berat isi yang lebih rendah, dengan nilai terendah pada campuran tanah + kapur $20 \%$ + petrasoil.

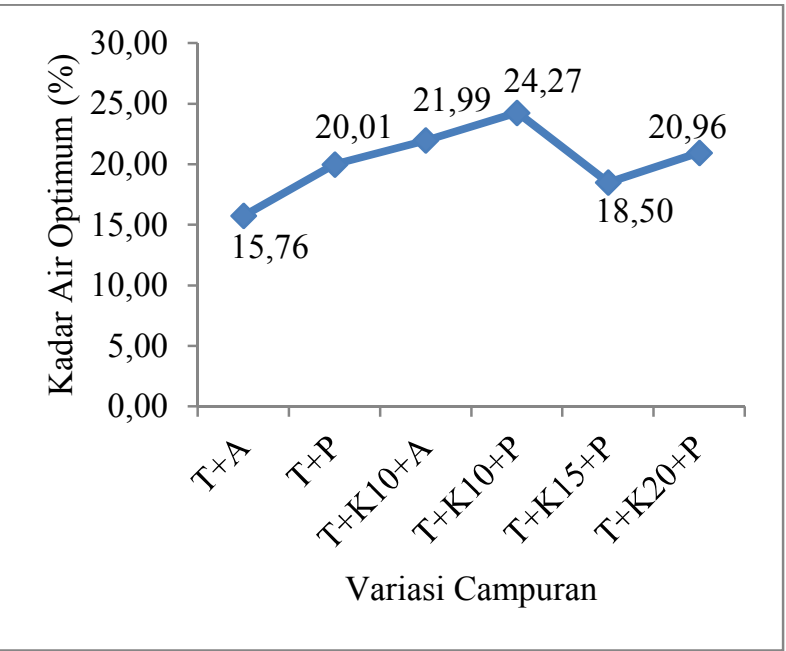

Gambar 2. Hasil Pengujian Kadar Air Optimum

Dari Gambar 2, dapat dilihat bahwa terjadi peningkatan kadar air optimum tertinggi pada variasi perbandingan tanah + $10 \%$ kapur + petra, yaitu sebesar $24,27 \%$.

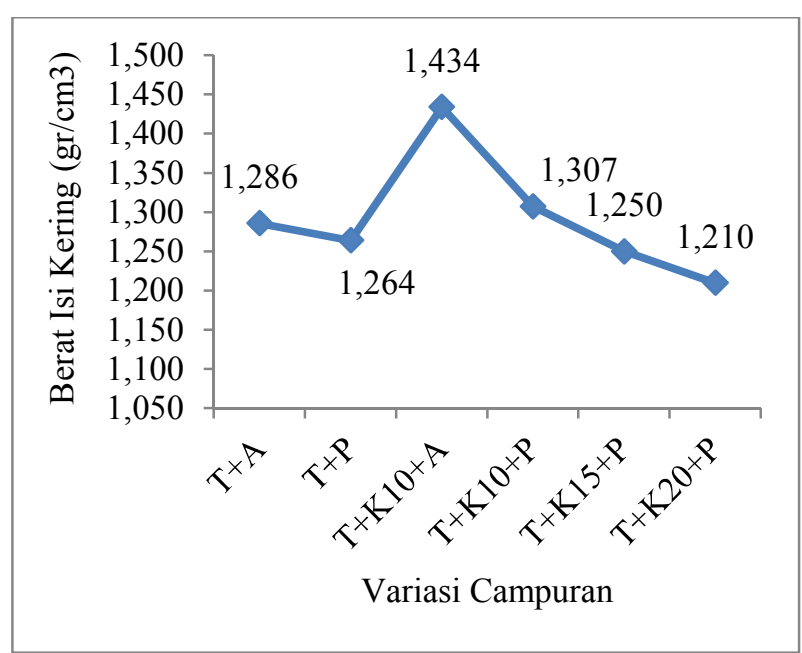

Gambar 3. Hasil Pengujian Berat Isi Kering

Gambar 3 menunjukkan bahwa berat isi kering tertinggi pada variasi pencampuran tanah $+10 \%$ kapur + air, yaitu sebesar 1,434 $\mathrm{gr} / \mathrm{cm}^{3}$.

\subsection{Hasil Pengujian Kekuatan Geser}

Pengujian kekuatan geser dilakukan untuk mendapatkan nilai sudut geser, nilai kohesi, dan nilai kekuatan geser dari kondisi tanah dalam 6 variasi campuran.

Hasil pengujian kekuatan geser dapat dilihat pada Tabel 3, sedangkan nilai kohesi dapat dilihat pada Gambar 4. 


\begin{tabular}{|c|c|c|c|}
\hline \multicolumn{4}{|c|}{ Tabel 3. Hasil Pengujian Kuat Geser } \\
\hline No. & Variasi & $\begin{array}{l}\text { Nilai Kohesi } \\
\text { (C) Kpa }\end{array}$ & $\begin{array}{c}\text { Sudut } \\
\text { Geser }(\theta)\end{array}$ \\
\hline 1 & Tanah + Air & 19,81 & 26,20 \\
\hline 2 & $\begin{array}{l}\text { Tanah }+ \\
\text { Petrasoil }\end{array}$ & 8,50 & 20,16 \\
\hline 3 & $\begin{array}{l}\text { Tanah + Kapur } \\
10 \%+\text { Air }\end{array}$ & 4,89 & 35,10 \\
\hline 4 & $\begin{array}{l}\text { Tanah + Kapur } \\
10 \%+ \\
\text { Petrasoil }\end{array}$ & 40,37 & 32,01 \\
\hline 5 & $\begin{array}{l}\text { Tanah + Kapur } \\
15 \%+ \\
\text { Petrasoil }\end{array}$ & 36,17 & 23,38 \\
\hline 6 & $\begin{array}{l}\text { Tanah + Kapur } \\
20 \%+ \\
\text { Petrasoil }\end{array}$ & 52,41 & 30,66 \\
\hline 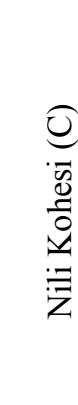 & $\left.\begin{array}{l}60 \\
50 \\
40 \\
30 \\
20 \\
10 \\
0\end{array}\right]$ & 40,37 & 52,41 \\
\hline & & riasi Campuran & \\
\hline
\end{tabular}

Gambar 4. Nilai Kohesi

Dari Gambar 4, dapat dilihat bahwa penambahan petrasoil pada tanah meningkatkan nilai kohesi, nilai kohesi tertinggi pada penambahan $20 \%$ kapur + petrasoil, yaitu sebesar 52,41 Kpa. Dengan meningkat nya nilai kohesi maka keterikatan antara partikel tanah semakin kuat sehingga dapat meningkatkan nilai kuat geser tanah. Hal ini menunjukkan bahwa penambahan petrasoil dan $20 \%$ kapur pada tanah dapat meningkatkan nilai kohesi pada tanah sebesar $38 \%$ dari nilai kohesi tanah asli dengan air.
Sedangkan nilai sudut geser dapat dilhat pada Gambar 5.

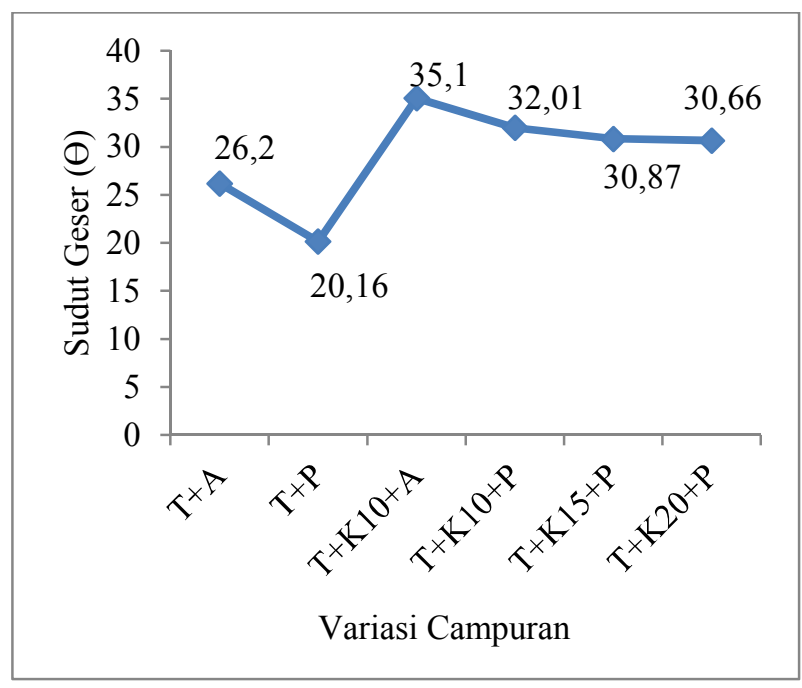

Gambar 5. Nilai Sudut Geser

Dari Gambar 5, dapat dilihat bahwa penambahan kapur dapat meningkatkan nilai sudut geser pada tanah, nilai sudut geser tertinggi pada penambahan $10 \%$ kapur + air, yaitu sebesar $35,1 \%$, dan pada $10 \%$ kapur + petra susut geser sebesar $32,01 \%$, ini berarti dengan penambahan $10 \%$ kapur pada tanah dengan campuran air atau petrasoil dapat meningkatkan sudut geser tanah, dimana semakin tinggi sudut geser maka bidang kontak akan semakin besar sehingga kemampuan menahan geser juga semakin meningkat.

Perendaman benda uji sebelum pengujian dapat mempengaruhi hubungan antara nilai kuat geser dan nilai kohesi, dimana pada pengujian langsung tanpa rendaman dapat menyebabkan nilai kohesi dan sudut geser menjadi tidak berbanding lurus [7] [8].

\section{Kesimpulan}

Penambahan kapur dan petrasoil pada tanah dapat meningkatkan nilai kohesi tanah, semakin besar persentase penambahan kapur akan menyebabkan peningkatan nilai kohesi, nilai kohesi tertinggi pada variasi petrasoil dan kapur 20\%, yaitu sebesar 52,41 Kpa. Sedangkan sudut geser tanah tertinggi pada 
variasi $10 \%+$ petrasoil, yaitu sebesar $35,10 \%$.

\section{Saran}

Penelitian lanjutan dapat dilakukan dengan melakukan perendaman pada petrasoil dan kapur agar antara kapur, tanah, dan petrasoil dapat menjadi senyawa terlebih dahulu.

\section{Ucapan Terima Kasih}

Kami ucapkan terimakasih kepada Politeknik Negeri Sriwijaya atas fasilitas dan pendanaan yang telah diberikan untuk terselesaikannya penelitian ini.

\section{Daftar Pustaka}

[1] H.C. Hardiyatmo, "Mekanika Tanah I," Gadjah Mada Unibersity Press, Yogyakarta.

[2] A. Willy, Iswan, M. Jafri, "Korelasi Kuat Tekan dengan Kuat Geser pada Tanah Lempung yang Didistribusi dengan Variasi Campuran Pasir," JRSDD, Maret, vol. 3, no. 1, pp. 157-170, 2015.

[3] A. Herius, Indrayani, A. Hasan, A. Mirza, "Addition Effect of Petrasoil Additive Material on CBR Value of Soil in Swamp Areas," Indonesian Journal of Environmental Mangement and Sustainability, 2019, pp. 67-70, https://doi.org/10.26554/ijems.2019.3.2.
[4] Indrayani, A. Herius, A. Hasan, A. Mirza, "Comparison Analysis of CBR Value Enhancement of Soil Type in Swamp Area by Addition of Fly Ash," Science and Technology Indonesia, 2018, pp. 73-76, http://doi.org/10.26554/sti.2018.3.2.

[5] A. Hakam, R. Yuliet, R. Donal, "Studi Pengaruh Penambahan Tanah Lempung pada Tanah Pasir Pantai Terhadap Kekuatan Geser Tanah," Jurnal Rekayasa Sipil, 2010, pp. 11-22.

[6] A. Wibawa, "Pengaruh Penambahan Limbah Gypsum terhadap Nilai Kuat Geser Tanah Lempung,” Jurnal Fropil, 2015, pp. 65-71.

[7] R.P. Rambe, L. Afriani, Iswan, “ Pengaruh Fraksi Lempung Terhadap Nilai Kohesi dan Indeks Plastisitas", JRSDD, Volume 4, No. 2, 2016, pp. $205-214$.

[8] Indrayani, A. Herius, Daiyan Saputra1, Al Muhammad Fadil, "Analysis of The Effect of the Addition of Fly Ash and Petrasoil on The Soil Shear Strength of The Swamp Area," Indonesian Journal of Environmental Management and Sustainability, Vol. 4, No. 1, Maret, 2020, pp. 10-13, https://doi.org/ 10.26554/ ijems.2020.4.1.10-13. 